\title{
Anaphylaxis to Chlorpheniramine Maleate and Literature Review
}

\author{
Yong Won Choi, Min Je Jung, Hye One Kim, Bo Young Chung, Chun Wook Park \\ Department of Dermatology, Hallym University Kangnam Sacred Heart Hospital, Seoul, Korea
}

Chlorpheniramine maleate is commonly used antihistamine. Since antihistamines are the main therapeutic agents for symptomatic treatment of urticaria, anaphylaxis to antihistamines may lead to errors in diagnosis and treatment. We report a case of anaphylaxis induced by chlorpheniramine maleate confirmed by intradermal test. A 35-year-old female experienced history of anaphylaxis after intramuscular injection of chlorpheniramine maleate. Skin prick test was negative, but intradermal test was positive. Patient also experienced mild dizziness after intradermal test and refused to perform any further evaluation such as oral challenge test. Anaphylaxis for chlorpheniramine maleate is very rare but should be considered. (Ann Dermatol 31(4) 438 441, 2019)

\section{-Keywords-}

Anaphylaxis, Chlorpheniramine, Histamine $\mathrm{H} 1$ antagonist, Intradermal tests, Urticaria

Received March 27, 2018, Revised June 11, 2018, Accepted for publication June 15, 2018

Corresponding author: Chun Wook Park, Department of Dermatology, Hallym University Kangnam Sacred Heart Hospital, 1 Singil-ro, Yeongdeungpo-gu, Seoul 07441, Korea. Tel: 82-2-829-5221, Fax: 82-2-832-3237, E-mail: dermap@hanmail.net

ORCID: https://orcid.org/0000-0003-4512-8668

Bo Young Chung, Department of Dermatology, Hallym University Kangnam Sacred Heart Hospital, 1 Singil-ro, Yeongdeungpo-gu, Seoul 07441, Korea. Tel: 82-2-829-5221, Fax: 82-2-832-3237, E-mail: victoryby@naver.com ORCID: https://orcid.org/0000-0002-2795-0140

This is an Open Access article distributed under the terms of the Creative Commons Attribution Non-Commercial License (http://creativecommons. org/licenses/by-nc/4.0) which permits unrestricted non-commercial use, distribution, and reproduction in any medium, provided the original work is properly cited.

Copyright $₫$ The Korean Dermatological Association and The Korean Society for Investigative Dermatology

\section{INTRODUCTION}

$\mathrm{H} 1$ antihistamines are widely used anti-allergy drugs. Even though the tolerability and safety of $\mathrm{H} 1$ antihistamines in humans have been widely established, hypersensitivity reactions have been reported since the $1940 \mathrm{~s}^{1}$. Chlorpheniramine maleate (CPM) is a classic, first-generation antihistamine commonly used for urticaria, rhinitis, and conjunctivitis. CPM belongs to the chemical group called alkylamines. Like the other antihistamines, it inhibits $\mathrm{H} 1$ receptors in a non-selective way, antagonizing the effects of histamine.

Because its action is not selective, it can inhibit peripheral and central cholinergic receptors and serotoninergic receptors, inducing drowsiness, dizziness, constipation, anxiety, nausea, restlessness, dry mouth, shallow breathing, problems with memory or concentration, tinnitus, and difficulty of urination ${ }^{2}$. Our case was diagnosed as CPM anaphylaxis by history taking and positive intradermal test.

\section{CASE REPORT}

A 35-year-old female visited an emergency room for discomfort of throat and dizziness. Her heart rate was 102 but blood pressure was in normal range. She had been taking antihistamines (azelastine $1 \mathrm{mg} / \mathrm{d}$ and piprinhydrinate $3 \mathrm{mg} / \mathrm{d}$ ) for a week due to pityriasis rosea presenting with erythematous scaly macules and patches on her trunk. She had had a CPM intramuscular injection four hours before visiting the emergency room at a local clinic. Blood test parameters including eosinophil count, total immunoglobulin E (IgE) level, complement level, and antinuclear antibodies were within normal range. Her symptoms disappeared after six hours with fluid therapy and intravenous methylprednisolone sodium succinate (125 mg). She had a history of dizziness and throat discomfort after a 
previous antihistamine intramuscular injection.

Two months later, the patient underwent a skin-prick test in a dermatologic outpatient clinic, prepared with epinephrine, dexamethasone, and automatic electric defibrillator, by dermatologists. The results of skin prick tests with $\operatorname{CPM}(1,0.2,0.02$, and $0.002 \mathrm{mg} / \mathrm{ml})$, azelastine $(0.01$ and $0.001 \mathrm{mg} / \mathrm{ml})$, piprinhydrinate $(0.03$ and 0.003 $\mathrm{mg} / \mathrm{ml})$, fexofenadine $(1.8$ and $0.1 \mathrm{mg} / \mathrm{ml})$, epinastine $(0.1$ $\mathrm{mg} / \mathrm{ml})$, ebastine $(0.1 \mathrm{mg} / \mathrm{ml})$, and loratadine $(0.1 \mathrm{mg} / \mathrm{ml})$ were all negative.

In addition, intradermal tests with the same drugs were performed a week later (Fig. 1). CPM (2, 1, and $0.2 \mathrm{mg} / \mathrm{ml}$ ) showed positive reactions after intradermal testing of the patient. Results from similar tests were negative in three healthy control volunteers.

Fifteen minutes after the intradermal test, the patient felt mild dizziness, which was alleviated by a $5 \mathrm{mg}$ dexamethasone intramuscular injection. She refused to carry out any more diagnostic tests including oral challenge. Finally, she was diagnosed with anaphylaxis to CPM according to history taking and positive intradermal test. The patient was instructed to inform physicians about her hypersensitivities in the future. We received the patient's consent form about publishing all photographic materials.

\section{DISCUSSION}

Hypersensitivity drug reactions may not only be provoked by the pharmacologically active molecules, but also by inactive ingredients (e.g., additives and preservatives). This makes it difficult to identify causative ingredients ${ }^{3}$. Moreover, the lack of understanding of the mechanism of hy- persensitivity to antihistamines makes development of a diagnostic test more difficult.

Anaphylaxis, which is IgE mediated type 1 hypersensitivity reaction, can be diagnosed on the basis of rapidity of symptom occurrence and signs of release of cytokines of mast cells and basophils. This might include involvement symptoms of mucocutaneous, gastrointestinal (intraoral angioedema, nausea, emesis, dysphagia, abdominal cramping, diarrhea), respiratory (rhinitis, stridor, cough, hoarseness, aphonia, tightness in the throat, dyspnea, wheezing,

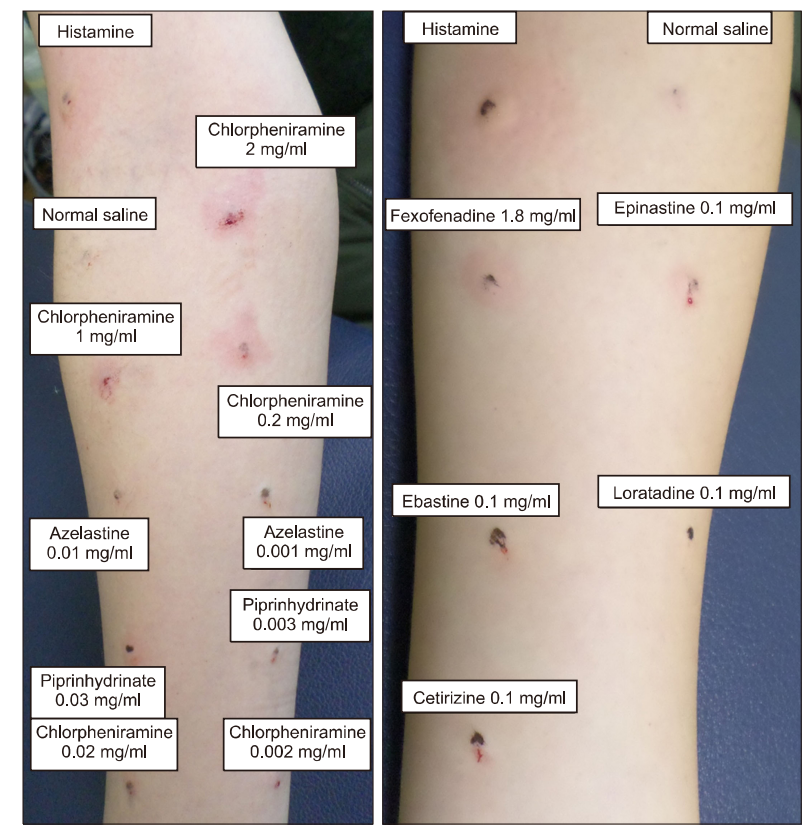

Fig. 1. Intradermal test result of various antihistamines (after 15 minutes).

Table 1. Reported cases of anaphylaxis due to antihistamines

\begin{tabular}{|c|c|c|c|c|c|c|}
\hline Author & Sex/age (yr) & Implicated drug & SPT & APT & IDT & $\mathrm{CT}$ \\
\hline Barranco et al. ${ }^{4}(1998)$ & Female/42 & Diphenhydramine & - & ND & + & + \\
\hline Cáceres Calle et al. $^{5}$ (2004) & Female/32 & Dexchlorpheniramine & - & ND & + & ND \\
\hline Weidinger et al. $^{6}$ (2004) & Female/47 & Mizolastine & - & ND & ND & + \\
\hline Gonzalo-Garijo et al. ${ }^{7}$ (2006) & Male/26 & Mizolastine & - & - & ND & + \\
\hline \multirow[t]{2}{*}{ Vythoulka et al. ${ }^{8}(2006)$} & Female/55 & Mizolastine & + & ND & ND & ND \\
\hline & Female/30 & Mizolastine & + & ND & ND & ND \\
\hline Thurot-Guillou et al. ${ }^{9}$ (2007) & Female/63 & Dexchlorpheniramine & - & ND & + & ND \\
\hline Afonso et al. ${ }^{10}$ (2009) & Female/30 & Cetirizine & ND & ND & ND & ND \\
\hline Inomata et al. ${ }^{11}$ (2009) & Female/34 & Hydroxyzine & - & ND & ND & ND \\
\hline Lee et al. $^{12}(2010)$ & Male/43 & Chlorpheniramine & + & - & ND & + \\
\hline Kim et al. $^{13}(2011)$ & Female/45 & Chlorpheniramine & + & + & + & + \\
\hline \multirow[t]{2}{*}{ Mur Gimeno et al. ${ }^{14}$ (2011) } & Female/48 & Dimenhydrinate & - & ND & ND & ND \\
\hline & & Diphenhydramine & ND & ND & - & + \\
\hline Lee et al. $^{15}$ (2015) & Female/33 & Chlorpheniramine & - & ND & - & ND \\
\hline Choi et al. (this case) (2019) & Female/35 & Chlorpheniramine & - & - & + & ND \\
\hline
\end{tabular}

SPT: skin prick test, APT: allergy patch test, IDT: intradermal test, CT: challenge test, +: positive, -: negative, ND: not described. 
hypopharyngeal or laryngeal edema, cyanosis), or cardiovascular (chest pain, arrhythmia, hypotension, presyncope, syncope, tachycardia, bradycardia, orthostasis, seizures, shock). There have been many reports of urticaria due to antihistamines but cases of anaphylaxis are rare, particularly to CPM. Only a few cases have been reported in English medical literature (Table 1$)^{4-15}$.

Skin tests (prick, intradermal, and patch) have not shown adequate diagnostic reliability in identifying the causative antihistamine preparations. In our literature review, skin prick tests were positive in only 4 of $12(33.3 \%)$ in anaphylaxis to antihistamines cases and intradermal tests showed higher sensitivity of positive results in 4 of 6 $(66.7 \% \text { ) patients (Table } 1)^{4-15}$. Our patient was negative in the skin prick test but positive in the intradermal test. Patch tests have been used effectively for allergic contact dermatitis or fixed drug eruption to antihistamines but are not usually done in urticarial response or anaphylaxis to antihistamines. The low reliability of skin tests may be due to the low molecular weights of antihistamines, working as haptens, or to the fact that specific metabolites rather than the drugs themselves may develop hypersensitivity reactions ${ }^{16}$. Also, hypersensitivity drug reactions may not be to the pharmacologically active molecules, but rather to inactive ingredients. Therefore, testing with the native drugs may not produce positive reactions.

Injectable CPM includes benzyl alcohol and sterile water as inactive ingredients. There have been reports that benzyl alcohol can cause allergic reactions ${ }^{17}$. However, according to the fact that the patient had another history of anaphylactic reaction after intramuscular antihistamine injection, and that other injectable agents like methylprednisolone and dexamethasone which contain benzyl alcohol didn't induce anaphylaxis, it is likely that CPM itself is responsible for anaphylaxis in this case.

Since the 1990s, the basophil activation test has been widely used for diagnosing immediate allergic reactions. This is done through flow cytometry of the patient's blood sample, by discovering unique markers of basophil granulocytes $^{18,19}$. Its greatest advantage is safety: it is not performed directly on the patient. However, it does have the problems of limited sensitivity and availability.

Because the skin tests and in vitro tests are of limited value in diagnosing hypersensitivity to $\mathrm{H} 1$ antihistamines, the diagnosis should be primarily based upon the medical history, and confirmation, if needed, should be done using an appropriately designed oral challenge. However, such an oral challenge test can be dangerous in patients at risk for anaphylaxis, like the patient in this case.

The oral challenge test is the gold standard method for diagnosis but it is usually not performed. However, if need- ed, it should be carefully performed in medical facilities where immediate treatment can be initiated when severe side effects (like anaphylactic shock) manifest. Our patient refused the oral challenge test.

In conclusion there have been reports of urticaria for antihistamines, and even rarely anaphylactic reactions can occur. It is ironic that antihistamines, which are used as basic treatments for urticaria, can cause urticaria. This can be missed in the diagnostic process and physicians should be alert because it may also cause serious side effects such as anaphylaxis.

\section{ACKNOWLEDGMENT}

This study was supported by grants from the National Research Foundation of Korea (NRF), funded by the Ministry of Science, ICT \& Future Planning (NRF-2017 R1A2B4006252, 2018R1C1B6007998), the Korea Healthcare technology R\&D Project, funded by the Ministry of Health \& Welfare, Republic of Korea (HI17C0597), and the Hallym University Research Fund (HURF-2017-35, HURF-2017-52).

\section{CONFLICTS OF INTEREST}

The authors have nothing to disclose.

\section{ORCID}

Yong Won Choi, https://orcid.org/0000-0003-0607-5145

Min Je Jung, https://orcid.org/0000-0002-1037-2209

Hye One Kim, https://orcid.org/0000-0001-5846-0008

Bo Young Chung, https://orcid.org/0000-0002-2795-0140

Chun Wook Park, https://orcid.org/0000-0003-4512-8668

\section{REFERENCES}

1. Epstein E. Dermatitis due to antihistaminic agents. J Invest Dermatol 1949;12:151.

2. Simons FE. H1-Antihistamines: more relevant than ever in the treatment of allergic disorders. J Allergy Clin Immunol 2003;112(4 Suppl):S42-S52.

3. Hur $\mathrm{H}$. A case of recurrent urticaria induced by Tartrazine present in antihistamine. Korean J Dermatol 1998;36:742744.

4. Barranco P, López-Serrano MC, Moreno-Ancillo A. Anaphylactic reaction due to diphenhydramine. Allergy 1998;53: 814.

5. Cáceres Calle O, Fernández-Benítez M. Allergy to dexchlorpheniramine. Study of a case. Allergol Immunopathol (Madr) 2004;32:306-309.

6. Weidinger S, Mempel M, Ollert M, Elser I, Rakoski J, Köhn FM, et al. Anaphylaxis to mizolastine. J Allergy Clin Im- 
munol 2004;114:979-981.

7. Gonzalo-Garijo MA, Jiménez-Ferrera G, Bobadilla-González P, Cordobés-Durán C. Hypersensitivity reaction to mizolastine: study of cross reactions. J Investig Allergol Clin Immunol 2006;16:391-393.

8. Vythoulka A, Pitsios C, Kompoti E. Allergic reactions due to mizolastine. Ann Allergy Asthma Immunol 2006;97:262-263.

9. Thurot-Guillou C, Bourrain JL, Jacquier JP, Beani JC. Anaphylactic reaction to ranitidine and dexchlorpheniramine. Eur J Dermatol 2007;17:170-171.

10. Afonso N, Shetgaonkar P, Dang A, Rataboli PV. Cetirizineinduced anaphylaxis: a rare adverse drug reaction. $\mathrm{Br} J$ Clin Pharmacol 2009;67:577-578.

11. Inomata N, Tatewaki S, Ikezawa Z. Multiple H1-antihistamine-induced urticaria. J Dermatol 2009;36:224-227.

12. Lee SH, Jung HS, Yoon TY, Chang EJ, Kim MK, Kim KS. Allergic reaction to chlorpheniramine in a patient with aspirin-intolerant asthma. Korean J Asthma Allergy Clin Immunol 2010;30:55-58.

13. Kim MH, Lee $\mathrm{SM}$, Lee $\mathrm{SH}$, Kwon HS, Kim SH, Cho SH, et al. A case of chlorpheniramine maleate-induced hypersen- sitivity with aspirin intolerance. Allergy Asthma Immunol Res 2011;3:62-64.

14. Mur Gimeno P, Alfaya Arias T, Iglesias Aranzazu M, Lombardero Vega M, Sastre B. Anaphylactic shock caused by antihistamines. J Investig Allergol Clin Immunol 2011; 21:321-322.

15. Lee HS, Song WJ, Lee JW, Cho YY, Park HK, Kang MG, et al. Chlorpheniramine-induced anaphylaxis diagnosed by basophil activation test. Asia Pac Allergy 2015;5:177-180.

16. Brockow K, Romano A, Blanca M, Ring J, Pichler W, Demoly P. General considerations for skin test procedures in the diagnosis of drug hypersensitivity. Allergy 2002;57:45-51.

17. Curry EJ, Warshaw EM. Benzyl alcohol allergy: importance of patch testing with personal products. Dermatitis 2005; 16 : 203-208.

18. MacGlashan DW Jr. Basophil activation testing. J Allergy Clin Immunol 2013;132:777-787.

19. McGowan EC, Saini S. Update on the performance and application of basophil activation tests. Curr Allergy Asthma Rep 2013;13:101-109. 